\title{
FATORES QUE DIFICULTAM A IMPLANTAÇÃO DE MEDIDAS DE REMEDIAÇÃO EM ÁREAS CONTAMINADAS RELACIONADAS AOS POSTOS DE COMBUSTÍVEIS LOCALIZADOS NA PORÇÃO PAULISTA DA UGRHI-PCJ
}

\author{
Vanessa Almeida de Godoy ${ }^{1}$ \\ Lucy Gomes Sant'Anna² \\ Marcelo Takashi Misato ${ }^{3}$
}

Resumo: A água subterrânea é um recurso natural de extrema importância, mas vem sendo contaminada por diversas atividades, como por exemplo, os postos de combustíveis. Para lidar com essa contaminação a CETESB desenvolve desde a década de 90 procedimentos para o gerenciamento de áreas contaminadas. Entretanto, o que se verifica é que as etapas finais do gerenciamento, incluindo a implantação de medidas de remediação, não estão sendo realizadas em boa parte das áreas contaminadas. Neste contexto, este trabalho buscou levantar os fatores que dificultam a implantação de medidas de remediação nas áreas contaminadas relacionadas à postos de combustíveis, que tenham seus aquíferos afetados e que se localizem na porção paulista da UGRHIPCJ. Para isso, levantaram-se informações dessas áreas (tipo de contaminante, fonte de

\footnotetext{
${ }^{1}$ Mestranda do Programa de Geotecnia da Escola de Engenharia de São Carlos da Universidade de São Paulo (valmeida@usp.br).

${ }^{2}$ Professora Doutora do curso de Gestão Ambiental da Escola de Artes, Ciências e Humanidades da Universidade de São Paulo (Isantann@usp.br).

${ }^{3}$ Mestrando do Programa de Ciência Ambiental (PROCAM) na Universidade de São Paulo (takashimisato@gmail.com).
} 
contaminação e coordenadas UTM), relacionaram-se as áreas contaminadas ao tipo de aquífero onde elas ocorrem por meio de um SIG, entrevistaram-se proprietários de postos de combustíveis que ainda não implantaram medidas de remediação e entrevistaram-se profissionais que trabalham com o gerenciamento de áreas contaminadas. Os resultados obtidos mostram que os tipos de aquífero, de contaminante e de técnicas de remediação não são os principais fatores que dificultam a implantação das medidas. Esta dificuldade decorre da relação de fatores como custo, falta de incentivo, existência da cultura de não proteção do bem ambiental e problemas de comunicação entre bandeira, proprietários e órgão ambiental, fazendo com que os gestores ambientais dessas áreas necessitem estar preparados para lidar com a complexidade das relações existentes entre esses diversos fatores.

Palavras-Chave: Remediação. Área Contaminada. Posto de Combustível. URGHI-PCJ.

\section{INTRODUÇÃO}

As águas subterrâneas são aquelas que ocorrem abaixo da superfície terrestre e podem ser armazenadas na porosidade das rochas, solos e sedimentos cumprindo uma fase do ciclo hidrológico (MINDRISZ, 2006; KARMANN, 2000; IRITAN e EZAKI, 2008). Essas águas correspondem a aproximadamente $98 \%$ de toda a água doce no estado líquido disponível para consumo no planeta, o que demonstra a grande importância estratégica da preservação deste recurso que, em muitos locais, já corresponde à parcela de água mais significativa para abastecimento público (CETESB, 1999; RUSSO, 2009). Devido às crises de abastecimento que muitos países vêm sofrendo nos últimos anos, a água subterrânea tem adquirido grande importância, pois é vista como uma alternativa para minimizar os efeitos da escassez hídrica (HIRATA, 1993). Além disso, cresce a percepção de que a água subterrânea é fundamental para o bem-estar tanto dos humanos como de diversos ecossistemas aquáticos, e é mais barata, quando comparada com a água superficial, para fins de abastecimento público (FOSTER et. al., 2006). No 
entanto, ela está sendo muito deteriorada em decorrência da urbanização e do crescimento econômico desenfreado.

Diversas atividades têm potencial de contaminar as águas subterrâneas, mas poucas são efetivamente as grandes responsáveis pela maioria dos casos de contaminação (HIRATA, 1993). As atividades realizadas em postos de combustíveis, de acordo com os dados disponibilizados pela Companhia Ambiental do Estado de São Paulo (CETESB, 2009), correspondem a 79\% do número total de áreas contaminadas registradas em 2009 no Estado de São Paulo. O número expressivo de áreas contaminadas relacionadas a essa atividade parece justificar a preocupação, principalmente quando se considera que a contaminação decorrente dos postos de combustíveis, por se originar geralmente de pequena quantidade de combustível vazado, muitas vezes imperceptível, pode ser negligenciada, aumentado a exposição do ambiente e das pessoas aos fatores de risco. Outro agravante é que as substâncias armazenadas nesses locais são muito perigosas e extremamente danosas à saúde da população, como os compostos da gasolina e do óleo diesel (RIBEIRO, LOURENCETTI e MARCHI, 2007).

Frente a problemas como estes, a CETESB, apoiada em legislações nacionais e estaduais, bem como em casos de sucesso em outros países, desenvolveu o Manual de Gerenciamento de Áreas Contaminadas. Este manual surgiu com o propósito de uniformizar as ações das instituições públicas e privadas envolvidas no gerenciamento de áreas contaminadas e de mostrar metodologias e formas de atuação a serem seguidas nas futuras ações da CETESB em termos de áreas contaminadas (CETESB,1999). Seu objetivo é ser um instrumento consultivo e propositivo. No entanto, a CETESB como órgão executor, de acordo com o Decreto n. 8.468/76 que regulamentou a Lei n.997/76, tem atribuição para estabelecer e executar planos e programas de atividade de prevenção e também de controle da poluição, além de levantar, organizar e disponibilizar todas as informações a respeito das fontes e dos meios afetados (CETESB, 1999). Desta forma, a CETESB, baseada no Manual de Gerenciamento de Áreas Contaminadas, em 22 de junho de 2007 através da Decisão de Diretoria n¹03/2007/CE, estabeleceu o novo procedimento para gerenciamento de áreas contaminadas, que prevê procedimentos específicos e estrategicamente posicionados para gerenciar aquelas áreas relacionadas a 
postos e sistemas retalhistas de combustíveis, atrelando a investigação ambiental ao licenciamento destes empreendimentos.

Segundo este procedimento, quando as concentrações de contaminantes estiverem acima dos valores alvo de remediação ou concentrações máximas aceitáveis (CMA's) calculadas para a área, a mesma passará a ser classificada como contaminada. Nesta situação será obrigatória a implantação de medidas de intervenção que podem ser medidas de remediação, de controle de engenharia ou de controle institucional, devendo ser aplicadas em conjunto ou isoladamente (CETESB, 2007). Segundo CETESB (2007, p.22), "a aplicação de técnicas de remediação deverá ser implementada quando existir risco à saúde acima do valor aceitável, necessidade de proteção de receptores ecológicos, ou mesmo quando ocorrerem situações de perigo", conforme pode ser visualizado na figura 10. É importante ressaltar que o prazo máximo para implantação e operação das medidas de intervenção em postos de combustíveis é de 5 anos, a partir da data da confirmação da contaminação.

Mesmo com a legislação e com os procedimentos previstos, o que se verifica é que ainda existem muitas áreas contaminadas no Estado de São Paulo que não contam com nenhuma medida de remediação em andamento, contrariando o procedimento adequado. Esta situação com muitas áreas contaminadas sem qualquer medida de remediação é encontrada na Unidade de Gerenciamento de Recursos Hídricos das Bacias Piracicaba, Capivari e Jundiaí (UGRHI-PCJ), conforme registrado no levantamento da CETESB realizado em 2009. Assim, tendo em vista que a UGRHIPCJ: 1) é importante na economia paulista; 2) abriga $12,1 \%$ da população de todo o Estado de São Paulo; 3) abrange grande área de recarga do Aquífero Guarani, além de vários outros aquíferos; 4) é importante fonte de recurso hídrico para a RMSP através do Sistema Cantareira, e 5) é a segunda UGRHI em número de áreas contaminadas relacionadas aos postos de combustíveis $(71 \%$ das áreas contaminadas na UGRHI-PCJ são decorrentes das atividades de postos de combustíveis), das 22 UGRHI existentes em todo o Estado de São Paulo, perdendo apenas para a UGRHI-Alto Tietê (CETESB, 2009), esta unidade de gerenciamento foi escolhida como área de estudo para verificação dos fatores que 
dificultam a implantação de medidas de remediação em áreas contaminadas relacionadas aos postos de combustíveis.

Considera-se fundamental que uma área com importância econômica, social e ambiental tão grande quanto a UGRHI-PCJ tenha seus aquíferos protegidos, mostrando preocupação não apenas com aspectos ambientais, mas também com a gestão integrada da bacia hidrográfica, a saúde e 0 abastecimento da população. A proteção e recuperação dos aquíferos podem ser alcançadas com o bom gerenciamento das áreas contaminadas. Mas para isso é fundamental que todos os procedimentos constantes de gerenciamento de áreas contaminadas da CETESB sejam seguidos e todas as medidas de remediação sejam efetivamente aplicadas quando forem necessárias.

\section{OBJETIVO}

Este trabalho buscou levantar os fatores que dificultam a implantação de medidas de remediação nas áreas contaminadas relacionadas a postos de combustíveis e que se localizam na porção paulista da Unidade de Gerenciamento de Recursos Hídricos dos Rios Piracicaba, Capivari e Jundiaí (UGRHI-PCJ).

É fundamental ressaltar que, o foco do trabalho apenas no território paulista da URGHI, gerido pela CETESB, não é suficiente para tratar da gestão integrada da bacia. No entanto, a metodologia desta pesquisa exigiu dados muito recentes não disponíveis para o Estado de Minas Gerais, o que dificultaria comparações e conclusões. Além disso, este trabalho é baseado nas falhas ocorridas durante a implantação da etapa de remediação da metodologia de gerenciamento de áreas contaminadas proposta pela CETESB, o que justificou a opção pelo estudo apenas da porção paulista da UGRHIPCJ (Figura 1). 


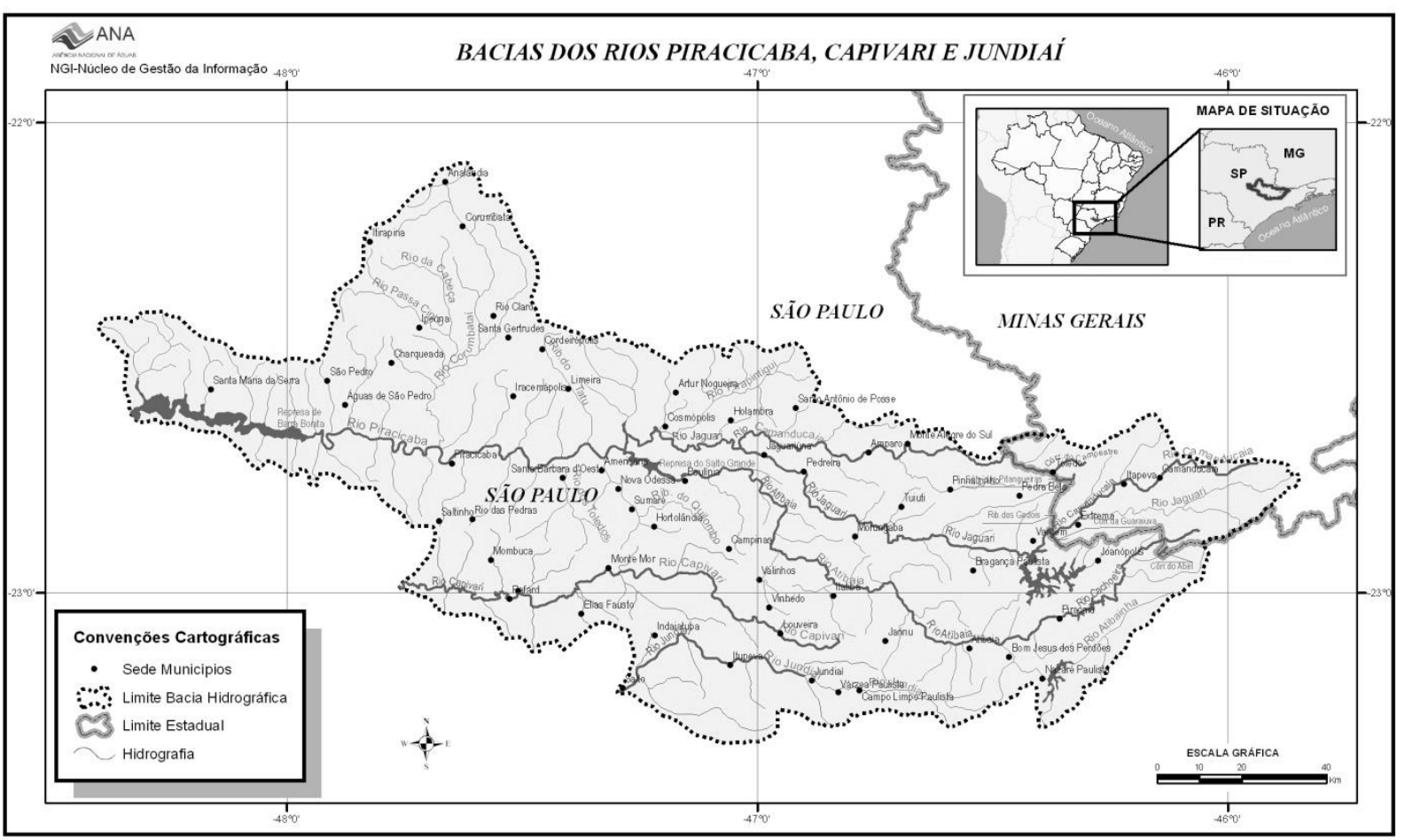

Figure 1 Mapa de Localização da UGRHI-PCJ Fonte: Agência Nacional das Águas (ANA) Disponível em: http://www2.ana.gov.br/Paginas/servicos/cobrancaearrecadacao/BaciaPCJ_Deliberacoes.aspx

\section{MATERIAIS E MÉTODOS}

Para a realização dessa pesquisa foram realizadas as atividades descritas a seguir:

\section{Levantamento das áreas contaminadas}

Foi efetuado o levantamento das áreas declaradas contaminadas por postos de combustível localizadas na porção paulista da UGRHI-PCJ, que tiveram seus aquíferos afetados e que não possuem nenhuma medida de remediação adotada.

Esse levantamento foi realizado a partir do banco de dados da CETESB, divulgado em novembro de 2009, onde foram coletados e tabelados os seguintes dados: 
- Fonte de contaminação

- Tipo de contaminante

-Coordenadas UTM ou endereço (para obtenção das coordenadas) quando as coordenadas não estavam disponíveis

\section{Associação das áreas contaminadas com tipos de aquíferos}

A partir do tabelamento das áreas contaminadas sem medidas de remediação, estas foram associadas aos tipos de aquíferos existentes nas áreas onde elas ocorrem. Esta correlação foi realizada através do uso do software Arcgis 9.3.1 por meio da sobreposição dos mapas de UGRHI's do Estado de São Paulo e do Mapa de Aquíferos do Estado de São Paulo (DAEE et. a.l, 2005). Após a sobreposição dos mapas, foram inseridas as coordenadas das áreas contaminadas. Para a elaboração do mapa de correlação das áreas contaminadas com o tipo de aquífero, foi necessário converter as coordenadas UTM das áreas obtidas no banco de dados da CETESB em coordenadas geográficas, o que foi efetuado utilizando-se o software Global Mapper 10.0.

Das 41 áreas identificadas que poderiam ser usadas para relacionar ao tipo de aquíferos, 3 tiveram de ser desconsideradas, pois seus endereços e suas coordenadas UTM declaradas no relatório da CETESB (2009) não encontravam-se nos limites da UGRHI-PCJ.

\section{Entrevistas}

Foram efetuadas entrevistas com proprietários dos estabelecimentos vinculados às áreas contaminadas e com profissionais que trabalham no gerenciamento de áreas contaminadas para levantamento de informações que auxiliassem na identificação dos 
fatores que têm retardado ou mesmo impedido a implantação de medidas de remediação nas áreas contaminadas por postos de combustíveis na porção paulista da URGHI-PCJ.

Estas entrevistas foram realizadas por telefone e buscaram, com perguntas abertas, identificar o ponto de vista do revendedor, já que ele, muitas vezes, é o principal responsável pela iniciativa de implantação das medidas de remediação, e poderia responder o porquê da não implantação. Além disso, buscou-se também identificar as dificuldades encontradas pelos profissionais que trabalham no gerenciamento de áreas contaminadas.

\section{RESULTADOS E DISCUSSÃO}

A UGRHI-PCJ possui 108 áreas classificadas como contaminadas. Dessas áreas, $87,1 \%$ tem como fonte de contaminação o armazenamento de combustíveis, demonstrando a falta de atenção ainda dada à substituição e ao monitoramento constante de vazamento dos tanques subterrâneos, conforme ressaltou MINDRISZ (2006) e HIRATA (2004). Além disso, $49 \%$ das áreas classificadas como contaminadas não possuíam nenhuma medida de remediação implementada até 2009, e 39\% das áreas não possuíam nenhuma medida de intervenção (remediação, medidas de engenharia, medidas institucionais, conforme definido por CETESB (1999)) (Figura 2). 


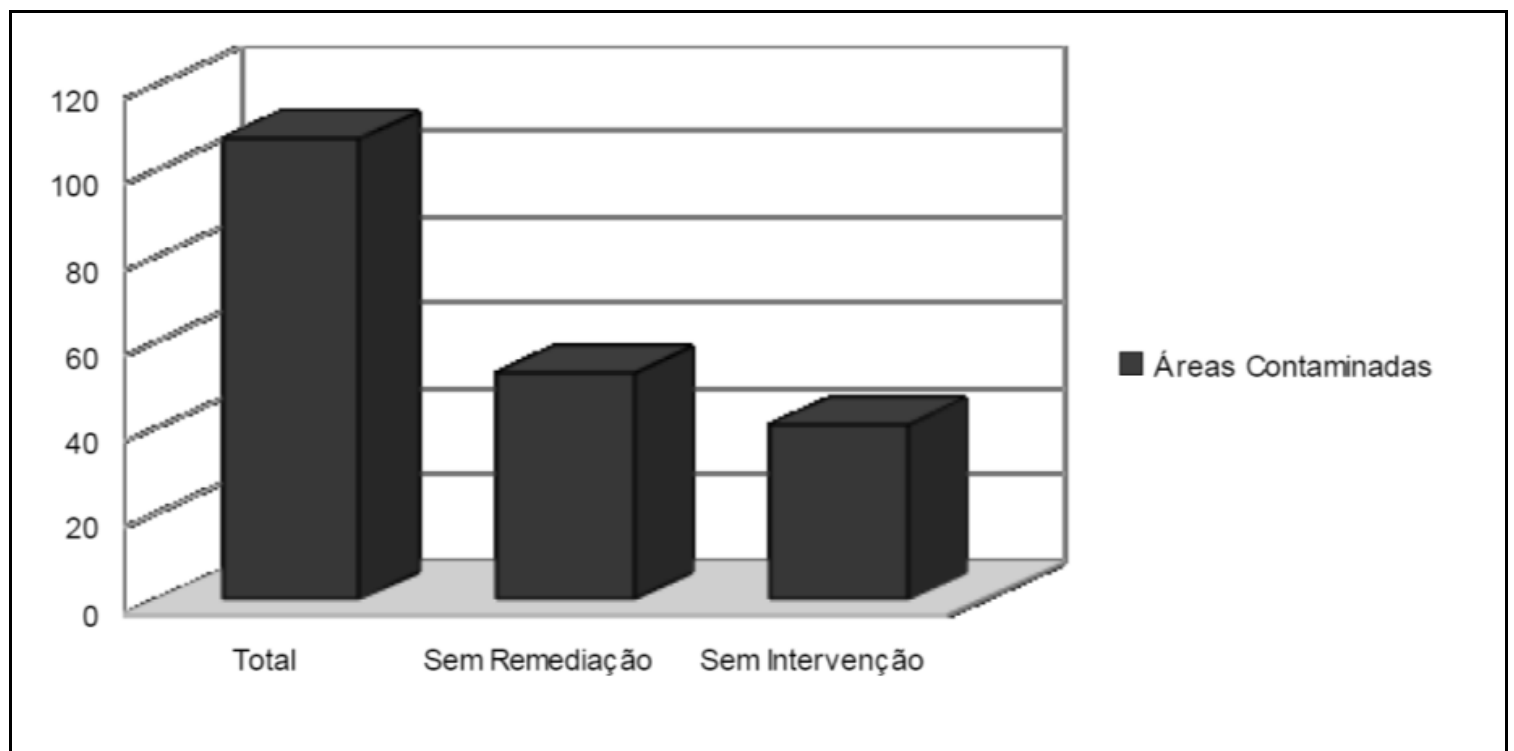

Figure 2 Áreas contaminadas sem medida de intervenção/remediação

Esses dados ressaltam as falhas nas etapas finais do gerenciamento de áreas contaminadas, já que a grande maioria das áreas inicia a investigação ambiental, mas no momento que é determinada a necessidade de intervenção o processo é interrompido. Isso demonstra a grande importância de se entender os problemas que estão ocorrendo nas etapas finais para que sejam tomadas as medidas mais adequadas de correção desses problemas.

No que diz respeito aos tipos de contaminantes, verificou-se que em $94 \%$ das áreas contaminadas os contaminantes eram combustíveis líquidos, sendo que em $32 \%$ das áreas os contaminantes eram PAH e em $53 \%$ das áreas os contaminantes eram solventes aromáticos. Com isso é possível verificar que os processos de remediação em áreas contaminadas provenientes das atividades de postos de combustíveis podem, cada vez mais, serem aprimorados, uma vez que os estudos precisam focar apenas algumas poucas classes de contaminantes. Essa pequena diversidade pode facilitar a tomada de decisão sobre qual técnica aplicar, e impede que o tipo de contaminante seja usado como justificativa para a não adoção de medidas de remediação. 
A correlação entre as áreas contaminadas e o tipo de aquífero mostrou a distribuição uniforme das áreas contaminadas sem medidas de remediação entre os aquíferos sedimentar e fraturado (Figura 3).

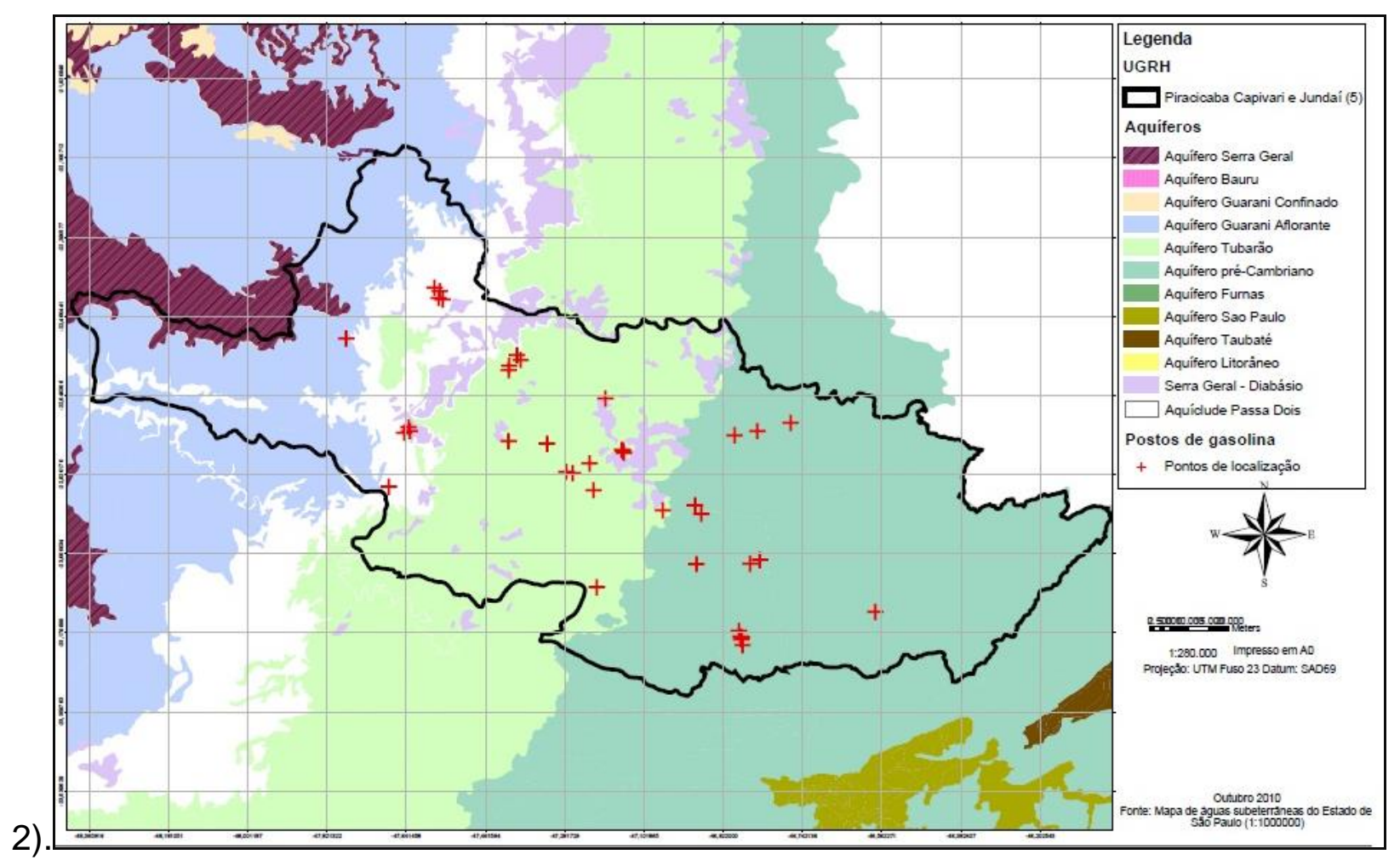

Figure 3 Áreas contaminadas por tipo de aquífero

A análise da Figura 3 mostra que existem 18 áreas contaminadas não remediadas nos aquíferos sedimentares e 20 nos aquíferos fraturados. Com a distribuição uniforme das áreas contaminadas sem medidas de remediação entre os tipos de aquíferos (sedimentar e fraturado), verifica-se então que o tipo de aquíferos, apesar de ser uma informação de extrema importância no momento da aplicação da técnica de remediação, não é um fator que claramente possa ser considerado como empecilho na implantação de medidas de remediação das áreas contaminadas.

Em $71 \%$ das áreas contaminadas que se enquadravam nos objetivos deste trabalho (não possuíam nenhuma medida de remediação e tinham seus aquíferos afetados) foi possível entrevistar os proprietários. Nos $29 \%$ restante não foi possível o 
contato com o dono do empreendimento devido a não receptividade ou número de telefone e endereços incorretos no banco de dados da CETESB e também em outros cadastros telefônicos.

Com a constatação de que o tipo de aquífero e o tipo de contaminante não podem ser considerados como fatores determinantes para a não implantação de medidas de remediação em áreas contaminadas, buscou-se levantar outros fatores que pudessem estar mais relacionados. Para isso foram entrevistados os proprietários dos postos de combustíveis que não possuíam nenhuma medida de intervenção adotada.

Estas entrevistas foram realizadas por telefone e buscaram, com perguntas abertas, identificar o ponto de vista do revendedor, já que ele, muitas vezes, é o principal responsável pela iniciativa de implantação das medidas de remediação, e poderia responder o porquê da não implantação. Alguns dados obtidos nas entrevistas são apresentados na forma de valores em porcentagem, os quais foram arredondados, sem perda dos resultados, para facilitar a compreensão. Informações dos postos, assim como de seus responsáveis, não foram divulgadas neste trabalho, uma vez que o objetivo é somente identificar os fatores que a classe "proprietários de postos de combustíveis" julga mais relevantes e não apontar a opinião deste ou daquele empresário.

Foram elaboradas 10 questões com base em alguns fatores que podem ser considerados fundamentais no momento da aplicação de técnicas de remediação como: 1) tempo, 2) preço, 3) problemas de comunicação (CETESB, posto, bandeira, consultorias, outros), 4) melhoria da imagem perante o cliente.

Com estas entrevistas observou-se que apesar de os questionamentos serem abertos, de maneira geral, os proprietários tenderam a levantar as mesmas dificuldades para implantação das medidas de remediação. Pôde-se perceber que as medias de remediação não são efetuadas por: i) não representarem diretamente alteração dos lucros, já que os clientes não se preocupam com o desempenho ambiental do empreendimento; ii) falta de interesse, por parte dos proprietários, pelas as questões relacionadas ao meio ambiente; iii) retardamento do processo com discussões e burocracias que, dependendo das características hidrogeológicas do aquífero, pode agravar ainda mais o cenário da contaminação; iv) problemas de comunicação entre 
consultorias-bandeiras-proprietários-CETESB; v) exclusão do proprietário do processo de gerenciamento de áreas contaminadas, com as decisões sendo tomadas exclusivamente pelas consultorias e/ou bandeiras, quando for o caso; vi) falta de incentivos, sanções ou outras ações estratégicas do órgão ambiental, a exemplo da necessidade de efetuar investigação ambiental para o empreendimento seja licenciado; e, vii) lentidão do órgão ambiental na notificação dos postos contaminados.

Após verificar o ponto de vista do revendedor e levantar alguns fatores que podem estar mais relacionados com a dificuldade de implantação de medidas de remediação, entrevistaram-se alguns profissionais que trabalham com o gerenciamento de áreas contaminadas. Estes profissionais também tiveram seus nomes preservados por motivos organizacionais. Entrevistou-se um engenheiro ambiental e um geólogo com 9 e 6 anos de experiência em gerenciamento de áreas contaminadas, respectivamente. Aos profissionais foi perguntado o que, na opinião deles, dificulta ou até mesmo impossibilita a implantação de medidas de intervenção em áreas contaminadas. Pediu-se que eles pensassem em dificuldades relacionadas aos proprietários de postos, órgão ambiental, bandeiras e fatores técnicos (tipo de aquífero, técnicas, custos e tempo) e nos incentivos que poderiam ser propostos.

As respostas dadas pelos profissionais foram muito parecidas entre si além de muito próximas das respostas dadas pelos proprietários, o que é um fator importante e mostra que existe conhecimento acerca do problema. Além disso, eles ressaltaram que é difícil apontar este ou aquele fator como o principal já que muitos estão relacionados e inter-relacionados, o que dificulta ainda mais o processo de remediação. De acordo com os profissionais entrevistados, no que diz respeito aos proprietários de postos, a grande dificuldade está relacionada com a falta de interesse pelas questões ambientais e, portanto, indisponibilidade financeira para arcar com os custos da remediação. Segundo esses profissionais, os proprietários não concordam em ter que arcar com os custos da contaminação. "É como se o lucro fosse direito dele, mas a contaminação fosse responsabilidade de todos, menos dele", afirmou um dos entrevistados. Para eles esta visão ainda está presente pelo fato dos proprietários de postos não perceberem a realização do gerenciamento da contaminação como um "algo a mais no negócio", mas 
apenas como custo, já que a clientela não é afetada por atitudes mais ou menos corretas no espaço subterrâneo, o que remete a impossibilidade dos clientes visualizarem os danos que o posto causa ao solo e à água subterrânea.

Segundo estes profissionais, a maioria dos proprietários de postos sequer sabe o que é uma investigação ambiental, seus objetivos e procedimentos básicos. Para eles 0 que melhor justifica essa situação é, novamente, a falta de interesse por parte dos proprietários. Esses profissionais acreditam que o fator não entendimento por motivos técnicos pode até ser importante, mas os proprietários não buscam entender os relatórios e discutir os resultados. Eles precisam dos relatórios apenas para cumprir solicitações da CETESB e evitar transtornos. No entanto, esses profissionais acreditam que, apesar de não saber o que está sendo feito e a importância e necessidade das etapas de gerenciamento, quando manifesta-se a necessidade de aplicar medidas de remediação, a grande maioria dos proprietários tem conhecimento da situação, sabe o que é remediação e não toma providência por alguns motivos comuns: 1) acham o processo muito caro; 2) espera até o último prazo oferecido pela CETESB, como uma forma de ganhar tempo; 3) espera apoio da bandeira e/ou 4) questionam os pareceres técnicos da CETESB com infinidade de cartas de justificativa a fim de ganhar tempo. Os profissionais lembraram o importante avanço nos processos de gerenciamento de áreas contaminadas, quando a CETESB atrelou a investigação ambiental ao licenciamento dos postos de combustíveis e acreditam que novas ações como esta deveriam ser pensadas, pois na maioria das vezes os procedimentos somente são adotados após alguma sanção ou obrigação legal.

Em relação ao órgão ambiental, estes profissionais disseram que o fator que mais retarda a implantação das medidas de remediação é a falta de pessoal, o que é ainda mais importante em cidades menores. Para eles a análise dos relatórios de avaliação de risco e plano de intervenção é muito lenta e, dependendo de fatores hidrogeológicos, pode fazer com que a contaminação se agrave muito em pouco tempo, principalmente quando for constatada a presença de gasolina e etanol juntos. Além disso, dizem que atividades de fiscalização e autuação deveriam ocorrer com maior frequência, pois as investigações, na maioria das vezes, são iniciadas apenas após o sofrimento de alguma 
sanção ou quando o proprietário precisa licenciar o empreendimento, questão retomada mais adiante.

No que diz respeito aos fatores técnicos, os profissionais são categóricos ao afirmar que "técnica de remediação não é problema em posto de combustível há muito tempo". Segundo eles, os contaminantes são sempre os mesmos voláteis e são, quando comparados com os contaminantes encontrados em indústrias, fáceis de remediar. Esses profissionais acreditam que atualmente no mercado as técnicas mais usadas e com melhor relação custo/benefício são as de extração multifásica (MPE), extração de vapores do solo e injeção de oxidantes (que na maioria das vezes é o peróxido) e bombeamento através de poços e bombas de sucção.

Entretanto, os profissionais lembraram o importante avanço nos processos de gerenciamento de áreas contaminadas, quando a CETESB atrelou a investigação ambiental ao licenciamento dos postos de combustíveis e acreditam que novas ações como esta deveriam ser pensadas, pois na maioria das vezes os procedimentos somente são adotados após alguma sanção ou obrigação legal. Com a entrevista dos profissionais, percebeu-se que existem fatores muito comuns apontados diretamente pelos profissionais e indiretamente ou diretamente pelos proprietários como, por exemplo, falta de interesse frente aos problemas ambientais. Além disso, verificou-se a importância das obrigações legais para que o processo de gerenciamento chegue ao fim. Discussões de interesses envolvendo bandeiras e postos, além de problemas institucionais como a falta de técnicos não são recentes e são conhecidos por todos, necessitando, desta forma, de maior atenção, já que estão prejudicando significativamente o processo. Entretanto, o que se evidencia é que mesmo sendo diversos os fatores que podem retardar ou até mesmo impedir a implantação de medidas de remediação em áreas contaminadas, existe um elo principal de ligação entre eles que é o custo.

\section{CONSIDERAÇÕES FINAIS}

O gerenciamento de áreas contaminadas é fundamental como parte da gestão integrada dos recursos hídricos. Desta forma, é imprescindível que os procedimentos 
existentes para uma boa solução dos problemas de contaminação sejam aplicados corretamente, o que não é verificado na UGRHI-PCJ. Com este trabalho foi possível identificar alguns fatores fundamentais que podem retardar ou mesmo impedir a aplicação de medidas de remediação em áreas contaminadas por postos de combustíveis, sendo eles:

- Não alteração dos lucros com a aplicação ou não das medidas de remediação, já que os clientes não se preocupam com o desempenho ambiental do empreendimento;

- Com isso, falta de interesse dos proprietários em investir em algo (remediação) que não alterará seus lucros;

- Falta de interesse pelas as questões relacionadas ao meio ambiente;

- Falta de iniciativa dos proprietários e retardamento do processo com discussões e questionamentos infundados apenas para ganhar tempo o que, dependendo das características hidrogeológicas, pode agravar ainda mais o cenário da contaminação;

- Problemas de comunicação entre consultorias-bandeiras-proprietários-CETESB;

- Exclusão do proprietário do processo de gerenciamento de áreas contaminadas, com as decisões sendo tomadas exclusivamente pelas consultorias e/ou bandeiras, quando for o caso;

- Falta de incentivos ou até mesmo sanções ou outras ações estratégicas do órgão ambiental, a exemplo da necessidade de efetuar investigação ambiental para o empreendimento seja licenciado;

- Lentidão do órgão ambiental na notificação dos postos contaminados.

Desta forma, foi possível identificar que o tipo de aquífero (sedimentar ou fraturado) não está diretamente associado com a falta de remediação. Alguns fatores fundamentais que podem retardar ou mesmo impedir a aplicação de medidas de remediação em áreas contaminadas por postos de combustíveis são o custo, falta de incentivo, falta de interesse dos proprietários, cultura de não proteção dos recursos naturais e problemas de comunicação. 


\section{REFERÊNCIAS}

COMPANHIA AMBIENTAL DO ESTADO DE SÃO PAULO. Relação de áreas contaminadas e reabilitadas no Estado de São Paulo: relatório técnico. São Paulo: CETESB, 2009.

Manual de gerenciamento de áreas contaminadas. Projeto CETESB-GTZ. Cooperação Técnica Brasil-Alemanha: relatório técnico. São Paulo: CETESB, 1999. 389p.

Sistema de licenciamento de postos II - quadros de exigências para o licenciamento ambiental de postos e sistemas retalhistas de combustíveis. São Paulo: $\quad 2007 . \quad$ CETESB, Disponível em: <http://www.cetesb.sp.gov.br/Servicos/licenciamento/postos/documentos/S695.pdf>. Acesso em: 15 junho 2010.

DAEE, IG, IPT, e CPRM. Mapa de água subterrânea do Estado de São Paulo Escala 1:1.000.000 - Nota Explicativa. São Paulo, 3v. 119P, 2005.

FOSTER, S.; HIRATA, R.; GOMES, D. D’ELIA, M.; PARIS, M. Proteção da qualidade da água subterrânea: um guia para empresas de abastecimento de água, órgãos municipais e agências ambientais. São Paulo, Servmar e Banco Mundial. 104p. 2006. Disponível em: $\quad<$ http://siteresources.worldbank.org/INTWRD/Resources/3364861175813625542/GroundwaterQualityProtectionGuide Portugese.pdf >. Acesso em 12 de setembro 2010.

HIRATA, R.C.A. Os recursos hídricos subterrâneos e as novas exigências ambientais: aspectos teóricos para a definição de proteção e controle. Revista do Instituto Geológico. São Paulo. v. 1, n. 12, p. 39-62, 1993.

KARMANN, I. Ciclo da água. In. TEIXEIRA, W.; TOLEDO, M.C.; FAIRCHILD, T.R.; TAIOLI, F. Decifrando a Terra. São Paulo, Oficina de Textos, p. 113-138. 2000

MINDRISZ, A. C. Avaliação da contaminação da água subterrânea de poços tubulares, por combustíveis fósseis, no município de Santo André, São Paulo: uma contribuição à gestão ambiental. 254p.Tese (Doutorado em Ciências na Área de Tecnologia Nuclear - Materiais) Instituto de Pesquisas Energéticas e Nucleares, Autarquia Associada à Universidade de São Paulo, 2006.

RIBEIRO, M.L., LOURENCETTI, C., MARCHI, M.R.R. Contaminação de água subterrânea por pesticidas: Avaliação Preliminar. Revista Química Nova, v.30, n. 3, p. 688-694, 2007.

RUSSO, A.S. Estimativa da vulnerabilidade de aquíferos utilizando sistemas de informação geográfica e geoestatística - UGRHI-PCJ. Dissertação (Mestrado em Hidrogeologia e Meio Ambiente) Instituto de Geociências, Universidade de São Paulo, 2009. 